\title{
Climate Change Education: A New Approach for a World of Wicked Problems
}

\author{
Anna Lebtonen, Arto O. Salonen and Hannele Cantell
}

\section{Pursuit of a Good Life on a Finite Planet}

A rapid growth of population and more materialistic ways of life have given rise to what many geologists now call the era of the Anthropocene. ${ }^{1}$ In the Anthropocene, it is human activities that are the main factor determining the future of civilization. Climate change is a wicked problem ${ }^{2}$ that threatens the continuity of life. According to the analysis of 11,944 scientific papers, written by 29,083 authors and published in 1980 journals, there is over a $97 \%$ consensus on anthropogenic global warming (Cook et al. 2013). The importance of climate is clear for humans as we need food, fresh water, fiber, timber and protection from hazards to survive and thrive. Climate influences crop productivity, disease, water scarcity or availability, and vulnerability to hazards (Sachs 2015).

A. Lehtonen $(\varangle) \cdot$ H. Cantell

University of Helsinki, Helsinki, Finland

A. O. Salonen

Faculty of Social Sciences and Business Studies,

University of Eastern Finland, Kuopio, Finland

e-mail: arto.salonen@uef.fi

H. Cantell

e-mail: hannele.cantell@helsinki.fi

(C) The Author(s) 2019

J. W. Cook (ed.), Sustainability, Human Well-Being, and the Future of Education, https://doi.org/10.1007/978-3-319-78580-6_11 
The effect of human activities raises significant questions for societies and their education systems. Increasing signals of ecological, cultural and social crises provokes questioning about current thinking, learning and behaviour. In the context of the Anthropocene, we need to learn what is necessary and what is possible in order to build a sustainable future. The key issue for education in the twenty-first century is how 9-10 billion people will be able to make life dignified on a finite planet. As John Dewey said, 'The conception of education as a social process and function has no definite meaning until we define the kind of society we have in mind' (Dewey 1915).

Our traditional world view is human-centered. Since the 1600 s, people started to understand the Earth as a giant reservoir, which secured energy and raw materials for human consumption. It was the beginning of a misunderstanding: people thought resources were limitless and inexhaustible, and thus began an alienation from the web of life. In recent decades, social harmony has been pursued by increasing consumption. Inflation, public debts and private loans have enabled us to increasingly use resources that do not exist. With the help of these resources, we have taken natural resources from the mines, forests and fields to make more and more commodities for human consumption. Together with cheap fossil energy, mass consumption has become a new normal in order to pursue a good life. Due to globalization, the consequences of mass consumption have not been very visible. Climate change is a symptom of severe unsustainability and an alarming signal: there is an urgent need for a change.

Our acts have socio-ecological impact. Every act matters, whether we see it or not. The thoughts, words and acts construct the social reality we are living in. The cultural norms, values and taboos are all implicit in culture. However, we can choose what we think about climate change. We can choose what kind of life and social reality we want to construct. The collective apathy and despair can transform to hope through collective experiences.

In this article, we define features of climate change education. We consider climate change as an example of the wicked problems in the era of the Anthropocene. We ponder what kind of societal and cultural transformations, thinking and learning are needed. Our main question is, how could we educate people for transformation towards a sustainable future? The following questions for education have also guided our thinking: 
(a) What kind of holistic change in thinking and action is needed for the construction of hope and of a sustainable future? (b) What kind of pedagogical approaches do we need for the construction of hope and of a sustainable future?

We start with illuminating the critical illusions of western culture and to where we need to step forward towards a sustainable future. Then, we offer practical approaches for climate change education to support the holistic thinking and learning we need in the Anthropocene. We end with pedagogical recommendations and a summary of the basics of a holistic approach to climate change education.

\section{Towards a Sustainable Future}

In the Western world, the progress of society is measured by quantity of capital flows. Financial goals are often put ahead of life values. The pace of life is getting faster and faster because the common assumption is 'more is better.' This has negative impact on both life satisfaction (which is one's cognitive appraisal of one's life as a whole) and climate change.

However, what humans require for happiness is life satisfaction as well as the health and well-being of our children, families, communities and natural environment. This is possible to realize in sustainable and resilient societies, comprised of personally fulfilled people, who use their potential fully for individual and common good and create sustainable solutions based on a socio-ecological understanding (Fadel et al. 2015, p. 7).

Combating climate change requires critical analysis of the reality we are constructing, and reflection on the roots of the problem including human-nature interdependency, individualism and consumerism. The perception of the problem frames possible solutions. We argue that there is a need for systemic thinking and widening the modern concept of knowledge to different ways knowing and holism. Apart from ecological, societal and cultural aspects, there is a need to address the issue of social change and the wicked problem of emotional and cultural denial of climate change. Emotional, somatic and embodied knowing are crucial aspects for mobilizing and engaging people for social change.

\section{From Materialism to Post-materialism}

Consumerism is a global trend and is strongly linked with climate change. However, mass consumption is widely considered a desirable 
goal, because it promotes economic growth. People rarely try to define how much is enough or how much is too much-they simply want to get more. This is an irresponsible search for short-term benefits without concerns for long-term consequences.

In the bigger picture, transforming societies from consumerism to sustainability is a more important issue to address than the control of population. For instance, a child born in the Western world will stress the Earth, causing as much environmental damage as 15-150 children born in developing countries (Ehrlich and Ehrlich 2004, p. 115). The global population is projected to reach $9-10$ billion in 2050 , but is projected to remain approximately the same in 2100 (UN 2013).

Ambivalent materialism:

Citizens of industrialized countries have reached material individualism that poses a threat to their own subjective well-being as well as environmental, economic and social sustainability. In these overdeveloped countries, people who pursue happiness through material gain tend to feel worse, which is related to negative appraisals of their life satisfaction (Roberts et al. 2015). Unprecedented consumption levels are problematic in overdeveloped countries, where the culture of 'having' is dominating and consumption is based on desires and wants instead of real needs. For example, consumption-based carbon dioxide emissions per person in Finland are the highest in Scandinavia and 9th highest globally (Caldeira and Davies 2010). Poorer countries, however, must have the right to develop fast to fulfil their citizens' basic needs.

Material prosperity is already becoming a barrier to the subjective well-being of people living in high consumption societies. People who prioritize prosperity and goods tend not to be satisfied with their life (Boyle et al. 2008). They experience less happiness and life satisfaction, have fewer pleasant emotions such as joy and contentment, and more unpleasant emotions such as anger and anxiety. They also tend to be more depressed and anxious. Even physical problems like headaches, stomach-aches and backaches as well as use of substances are associated with a strong focus on material values (Dittmar et al. 2014). Thus focusing on material wealth tends to neglect well-being problems, such as stress and fast pace of life, depression, loneliness, and ecologically destructive behaviour. Furthermore, weakening social relationships drive people to work and consume more (Bartolini 2014; Pieters 2013). Paradoxically, increased opportunities to spend more causes an inability to enjoy things obtained with money (Quoidbach et al. 2010). 
Post-material well-being:

Universal basic needs are fresh water, food, shelter, healthcare and education. What do we need more of and what less in order to increase our life satisfaction and subjective well-being on a finite planet? What should we pursue, when our basic needs are already fulfilled? The importance of material things decreases, when people reach more social capital - a form of capital that cannot be traded in markets and is not captured by monetary measures.

Shifting from materialism towards post-materialism means fundamental thinking and behaviour changes. These changes have multiple benefits as they improve subjective well-being. Yet what is most important is that they are necessary for human survival on a finite planet. Ronald Inglehart (1977) called a re-orientation from materialism to post-materialism a 'silent revolution' which is already occuring in Western societies. This paradigmatic shift towards full humanness was also described by Maslow (1954), Allardt (1976) and Schwartz (1992). See Table 11.1.

Post-material values emphasize human relationships and the meaningfulness of people's unique lives, including trust, community resilience and participation in the life of society as well as establishment, and flourishing of civil rights and personal expression (Inglehart 2008; Jackson 2009, pp. 143, 181-182; Nevarez 2011, p. 39). In everyday life, post-material behaviour means that the importance of ownership has decreased, services are used instead of owning goods and renewal of goods is motivated by real needs (Salonen and Åhlberg 2013, p. 385). Post-material values are growing in the countries where "a given generation grows up under conditions that permit it to take survival for granted" (Inglehart 2008, p. 145). Their basic needs are easy to fulfil.

Activation of post-material values has wide-ranging positive effects. Increasing post-materiality might not only result in the stability and

Table 11.1 Value shift from material values to non-material values

\begin{tabular}{lll}
\hline & Material values & Non-material values \\
\hline Inglehart (1977) & Materialism & $\begin{array}{l}\text { Post-materialism } \\
\text { Maslow (1954) }\end{array}$ \\
& $\begin{array}{l}\text { Physiological needs and safety } \\
\text { needs }\end{array}$ & $\begin{array}{l}\text { Social inclusion and needs of love, } \\
\text { needs of esteem and achievements }\end{array}$ \\
Allardt (1976) & Having & Loving and being \\
Schwartz (1992) & Security, conservation, & Openness to change, \\
& self-enhancement & self-transcendence \\
\hline
\end{tabular}


recovery of socio-ecological systems but also increasing health and happiness of people. At best, post-material values produce a culture of trust, which supplies future generations with opportunities for a good life (Dittmar et al. 2014).

\section{From Segregated Knowing and Cultural Dichotomies to Holism and Understanding Interconnectedness}

Our situation is not comparable to anything in the past. It is impossible, therefore, to apply methods and measures which at an earlier age might have been sufficient. We must revolutionize our thinking, revolutionize our actions.... (Albert Einstein 1948)

Climate change is a wicked problem: it is a huge, complex and systemic challenge and difficult to clearly define (Incropera 2015). Climate change is scientifically apparent, but it presents great scientific, economic and social complexity and uncertainty; solutions have unforeseen consequences. Different stakeholders provide conflicting information related to climate change, its relevance and impacts. Climate change produces profound ethical issues and lack of agreement on what the problem is, what the causes and consequences are and possible solutions that might exist. As a global issue, the implications and solutions need to be reflected both locally and globally. In addition, the challenge of maladaptive behaviour, the cultural and emotional aspects of climate change make it difficult to find efficient solutions or predict the results (Incropera 2015).

Climate change is a hyper, super wicked problem that cannot be solved with scientific knowledge, linear, mechanistic or analytical thinking alone (Kagawa and Selby 2010). Previously, the environmental problems people faced were much more local in character. If one factory runs its wastewater into a river, the river and lake nearby were polluted. The cause and the consequence were easy to recognize. Today's global environmental problems are complex mixtures of global, local, ecological, political, economic and social dynamics (Incropera 2015). Understanding and identifying the global and local perspectives and other interconnected phenomena demand new strategies of learning and thinking. Linear, fragmented modern thinking is not working in the context of wicked problems.

Modern dichotomies as roots of wicked problems:

Today's prevailing thinking has origins in modernism. Modern thinking is based on dichotomies such as nature-culture, human-animal, 
global-local, subject-object, mind-body, ration-emotion and individualsocial to mention the most problematic dichotomies fostering unsustainability. These modern dichotomies guide our problem solving strategies and management of life, how we relate with the world and how we perceive relationships between things. Dualistic thinking has resulted in linear, atomistic, fragmented thinking, ignorance of holistic relations and the exclusion of opposites from mental frames. We used to think our daily lives and the world around us fit into separate silos, which allowed us to solve our problems with fragmentary knowledge. This thinking has resulted in the geological era of the Anthropocene.

Awareness of interconnectedness has been missing at societal and academic levels. Natural and social sciences are inspecting the world from totally different perspectives, with distinct methods and concepts. Thus transdisciplinary research is almost impossible as researchers speak distinct languages. At the societal level, environmental, economic and cultural affairs are separated into different institutions. At schools organized into subject-oriented structures, teaching environmental issues is traditionally the domain of natural sciences and the human perspective and societal understanding is missing (Aarnio-Linnanvuori 2013). The holistic, systemic understanding of the world has thus been lacking.

Advertising, globalization and digitalization are accelerating separation from our vital web-of-life. Globalization has distanced us form the Earth's ecosystems; we can't perceive the eco-social consequences of our behaviour. Technology has created an illusion of boundless material and digital opportunities in 'any' world, virtual or real. The capitalist mode of mass production and consumption of technology is boosting unsustainable development (Snaza et al. 2014) by provoking effectiveness, competition and product-thinking. But we are not driven to sell nature as a product in the same way, preferring to sell ourselves and our identities. Neoliberalism, capitalism, globalization and digitalism interfere in our lives, our schooling and education and have impact on how we see, value and name things arising to ideologies that intensify modern dualisms and segregated thinking.

The problematic modern dichotomies and climate change (Fig. 11.1).

\section{Global-Local Dichotomy:}

Climate change is an issue without borders, yet the impacts vary locally. The relationship between global and local is thus complex because the relationships between causes and consequences are dynamic and unstable 


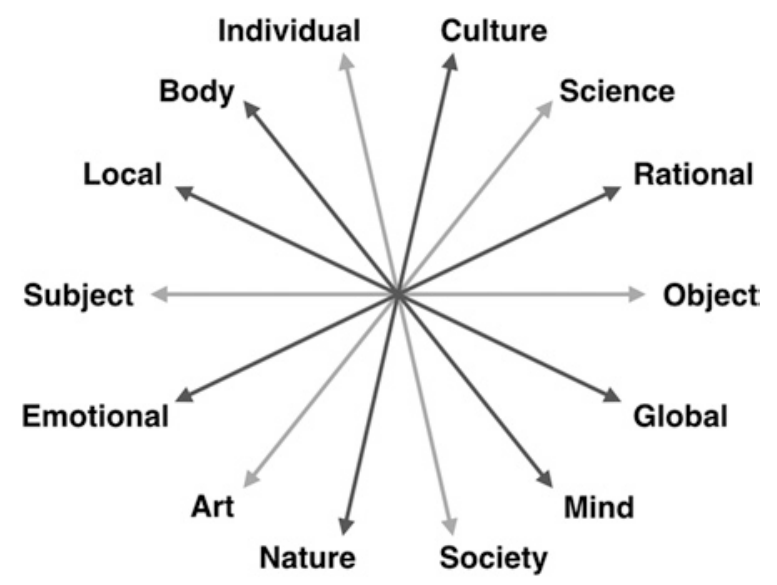

Fig. 11.1 Problematic dichotomies of modern thinking

and the question of responsibility is politically sensitive. There is a need for new kinds of theoretical concepts and knowledge about the interactions and relationships of various elements. What is especially needed is sensitive and empathetic understanding of people's perspectives in different localities. This means that in order to manage our own society and economy, we need to account for other societies and economies, as well as our actions that have global consequences. What people do, for example in the periphery of Finland affects individuals in other areas, even in other peripheries.

So, how are the local and global are connected? The global economy is a clear connector. For instance, a supply chain analysis by the researchers Womack and Jones followed a can of cola bought in London to illustrate the complexity of global markets. Bauxite, an aluminum ore is a key ingredient of the can was mined in Australia. Ore was transferred with trucks to a chemical reduction mill where it was cleaned. After that, ore was shipped to Sweden in a journey across oceans that took two months. Once in Sweden, 10 meter long aluminum rods were processed in a smelter. The rods were sent to Germany where they were heated and pressed into a thin sheet of aluminum. Coils of aluminum were shipped to England, where the aluminum sheets were formed into cans. The cans were then washed, dried, coated, and transported to a bottler. Meanwhile, sugar canes, farmed in French farms, were refined to sugar and shipped to England. Cola also contains phosphoric acid derived from 
a mine located in the United States. This mine uses energy equivalent to 100,000 people consumption of energy because food grade phosphoric acid requires a high degree of processing. Cola also contains caffeine that originates from a chemical factory nearby. Cans filled with cola are packed in cartons which are made of cellulose in a paper mill. The paper mill sources trees from Siberia, Sweden and Colombia. Finally, the cola cartons were transferred to the supermarket in which they were sold to consumers, usually within in three days. The average consumer drinks a can of cola in a few tens of seconds. The manufacturing of the can is more expensive than the liquid inside (Womack and Jones 2003).

\section{Nature-Culture Dichotomy:}

Climate change is the first radically systemic environmental problem humans have encountered and one that proves that social and ecological systems are interconnected. All ecological and human systems are implicated and are being or will be affected by the consequences of climate change in the short, medium or long term (Gonzalez-Gaudiano and Meira-Cartea 2010, p. 17). The illusion that humans are apart from nature is no longer tenable. It has led to a belief in human superiority and the subsequent right to control, use and benefit from nature which enables overconsumption. The binary opposition of human and biosphere is threatening to destroy human existence, for it not only allows the exploitation and destruction of flora and fauna, but it also sets humans against nature itself-nature is a resource waiting to be mined and exploited without regard for sustainability or the quality of life on the planet.

The future of coral reefs offers an example of complex socioecological systems and the need for systems thinking. As sea water warms and absorbs carbon dioxide, water becomes increasingly acidic, resulting in damage to vulnerable marine ecosystems. If the current trend continues, the first full ecosystem-corals - will extinct by the end of this century. It is an ecological problem, which also results in large-scale social challenge as 250 million people receive their daily food from coral reefs (Sale 2011). Without food, life is impossible and people will be forced from their homelands. Environmental migration affects the structures and stability not only of the countries of origin but also countries where immigration is directed. This poses risks to the peaceful co-existence of people.

Global warming is also one of the greatest challenges to social justice (World Bank 2012) and as a result, many countries have already included 
climate change in their security strategies. Poor people suffer the consequences of climate change the most, even though their way of life causes lower greenhouse gas emissions. Food, housing and mobility for the world's richest tenth of people produce $50 \%$ of global carbon dioxide emissions (Tukker et al. 2006). It is evident that a shift is needed toward understanding the nature-culture relationship; a new orientation integrating social and ecological concerns (Hirvilammi and Helne 2014; Norton 2005).

\section{Rational-Emotional Dichotomy:}

Climate change undermines the modern idealization of human rationality. In the Age of Human (Anthropocene), we are living in a fluid reality of natural conditions and existential threat. From a psychological perspective, human dependence on nature threatens the illusion of human autonomy and omnipotence (Lehtonen and Välimäki 2013). Denial of the existence and relevance of climate change or human, social or individual responsibility is still commonplace. Many deny the fact that consumer-based lifestyles are in crises and need to change (Norgaard 2011). People tend to see a temperate climate as preferable and/or rely on optimistic myths deriving from the Enlightenment: the future will always be better and of our species has known how to overcome other critical moments in the past (Gonzalez-Gaudiano and Meira-Cartea 2010).

The modern idealization of rational thought has led to a restricted understanding of human behaviour. The ideal of pure rationality has isolated knowing from emotions and thus fosters an instrumental attitude toward the world. The representation of nature as a resource is strong even in the field of Education for Sustainable Development (ESD) (Selby 2010). By presenting climate change as curable with current systems and tools limits focus on the human dimension and the crises arising from the disconnect between humans and the biosphere. Climate change education is often focused on developing a scientific understanding of the phenomenon, technological solutions and a more benign form of consumerism; thus the ethical dimension of climate change tends to remain rhetorical. The critical aspects of our humanity-and how they are threatened by our own actions - are largely ignored (Selby 2010).

The culpability of our behaviour in the looming climate crisis challenges most curricula and pedagogies. Education and schooling has traditionally focused on cultivating rational minds while emotions and the body as a component of learning have been neglected 
(Selby 2010, p. 38). In addition, despite the imperative to educate active citizens, students are often not treated as individuals with free will (Wolff 2011, p. 99). Educating active agency is often realized only in rhetoric as the need to control has prevented student-centred learning (Rainio 2008).

Climate change is a hybrid theme essentially founded in uncertainty and thus requires the combination of both intuitive and rational understanding. It impossible to control or even identify all the relevant variables and to know how these are linked to each other (GonzalezGaudiano and Meira-Cartea 2010, p. 14). It is almost unachievable to make predictions and move from the global scale to regional and subregional knowledge in the context of climate change. In addition, emotional literacy and empathy are needed to find efficient local solutions to a global problem.

\section{Mind-Body Dichotomy:}

Cartesian dualism-understanding the mind as separate from the bodyis indirectly influencing our behaviour and is partly to blame for the destructive over-consumption of the Western world. The bodily connection of Western people has weakened because marketers, whose tools are enhanced by digitalization, strengthen the confusion between needs and desires. We are affected continuously by advertisers working through all medias and the net effect is individuals don't know what they need or what is good for them.

Scientific knowledge built from a tradition of objectivity and empiricism has also furthered the neglect of embodied knowing (GonzalezGaudiano and Meira-Cartea 2010). People are told not rely on perception, senses, embodied, intuitive or emotional knowing but, scientific research-based information. The predominant belief is that scientific knowledge is the sole source of the truth and those empowered by science tend to know better what is needed than the average citizen.

The positivistic ideal of objective, value-neutral knowledge has dominated the natural sciences which rely on a materialistic ontologyeverything is understood to be measurable-in the pursuit of stable and generalizable knowledge. In the social sciences, the ideal of objectivismstable, objective knowledge generated from positivistic research-has enhanced the gap between theory and practice. Objective knowing has been isolated from and independent of the experiencing subject (i.e., the person observing and knowing). The modern ideals of objectivity and 
rationality have disconnected us from values, embodied and emotional knowing. How we perceive, receive or reject the messages of our environments, our bodies and emotions should have focus in education.

In this section, we have looked at the modern dichotomies of nature-culture, rational-emotional, mind-body, and local-global. The following section "From Knowledge and Rationalism to Holism, Intuition, Embodied and Emotional Awareness", deepens the discussion of the interconnectedness of rational-emotional, and mindbody. The rest of the modern dichotomies not yet clarified, but crucial from the perspective of climate change education are opened and analyzed in later sections. Individual-social is critically evaluated in the context of individualism ("From Individualism to Creative, Collective Collaboration"). Art's relationship to science is discussed within the section about Art-based education ("Art-Based Learning"). And in the end of our chapter, our pedagogical recommendations reveal our meta-model of interconnectedness - the ultimate aim of climate change education.

\section{From Knowledge and Rationalism to Holism, Intuition, Embodied and Emotional Awareness}

Facing crises like climate change promotes existential questions and critical reflections such as: do we have a future? Why are we here? What is the meaning of the life? Climate change could have a great potential for transformative learning and promote reevaluation of value-hierarchies. But reflection on climate change naturally evokes intense feelings (Naess 2008 , p. 35 ), which are not easy to manage. Nevertheless, emotions, embodied and intuitive knowing have remarkable value in our search for vital knowledge for survival.

How we react and handle our emotions and listen to our bodies, is largely a cultural question. Eco-anxiety might explain indifference and other difficulties coping with climate change and imagining the future, which might result in the denial of climate change. Instead of not caring, people might in fact care too much, and resort to psychological defenses or paralyzing anxiety, apathy and helplessness (Weintrobe 2013; Pihkala 2017).

Emotions link the inner and outer reality; they are signals, connecting us with values (Nussbaum 2003). There are no good or bad emotions, but the difficulties of coping with challenging emotions easily leads to 
becoming disconnected from the source anxiety. Nevertheless, by listening to emotions and our bodies, we can know what is good for us and what is not and we can connect with our needs, emotions and values. Ignoring the signals of our bodies and suppressing emotions leads to stress and illness.

"What is good life, goes primarily through emotions" (Naess 2008, p. 23). Information becomes alive and meaningful, if we experience it with our bodies (Snaza et al. 2014). The experience of our existencebeing alive-is located in our body. Our identity is strongly embodied in our bodies: how we see, react and feel; our emotions are manifest in our bodies. Through sensory experiences, we can sense the connection with other people and with nature.

How can we engage learners in processes that is both liberating and empowering? We need to develop emotional literacy in education that helps pupils face anxiousness and emotions in a constructive way. In order to do this, we need to find ways of facilitating learners' abilities to name and frame their own ideas and concerns about future, and their positionality and potential for change (Wayman 2009, p. 95).

Emotions need time and space:

Challenging emotions can have functional value. Positive feelings and emotions activate us while negative, challenging emotions can stop us or prevent action. Aggression and other negative feelings are necessary to motivate behaviour change and action. Expression and reflection on challenging emotions such as sorrow, grief and anger can promote consciousness of crisis, awareness of the borders of sustainability and the need to change. When given space and support, facing challenging emotions and using them in a constructive way can result in empowerment, motivation and activating feelings of joy (Naess 2008, pp. 78-79).

Climate change presents a peculiar problem for our emotions. In order to cope with shock, uncertainty, change and then adapt to a new situation, individuals need social support and should not be left alone when facing crises. However, there is a real danger of emotional manipulation or transference when teaching about climate change (Österlind 2012). Becoming worried about cynical and careless attitudes toward the environment can threaten an individual's sense of security and frighten them with visions of an apocalyptic future. However, it is important that an emotional response to climate change should not be forced or coerced. The emotional response must have time and space for expression and critical reflection either individually or collectively. 
Empathy promotes caring and awareness of connectivity:

Ethical thinking and behaviour is strongly linked with empathy. We care for the things to which we are personally connected. We need to experience this connection with other people and nature in order to become motivated to take care of them (Martusewicz et al. 2014). Empathy promotes understanding about external realities and, therefore, enables the possibility of greater connectivity. Global awareness and collective solutions for climate change require empathic understanding of people's need in different localities and caring for people especially vulnerable to climate change.

Empathy builds on self-awareness. The more open we are to ourselves, the more we are able to understand other people's experiences (Goleman 2006, p. 96). Having emotional connectivity with other people and other living creatures can increase one's awareness of purpose and meaning in life. Caring acts and taking responsibility, building initiatives for sustainability all enforce positive feelings, a sense of identity and, therefore, subjective well-being. Thus, a value-oriented life marked by contribution can be highly satisfying and motivating, and deepen one's sense of purpose. Understanding interconnectedness with nature and other people can promote hope.

Hope is a virtue, a habit of finding meaning and resilience, and not giving up (Orr 2009, p. 182). Constructive hope is the ability to see something meaningful and promising after encountering a challenging situation. It is based in part on trust in other people working toward the common good and trust in one's own ability to influence problems in a positive direction (Ojala 2012; Pihkala 2017). Educators and leaders have an important role in promoting constructive hope by demonstrating a caring attitude, and manifesting caring in practice, even in the face of collective denial about the criticality of climate change (Lehtonen and Välimäki 2013; Pihkala 2017).

To conclude, the whole spectrum of emotions and feelings, caring and careless attitudes - the entire emotional range-should be given space for expression. All opinions and taboos, the questions not often asked and even denialist attitudes should have the right to exist and be expressed. One way to foster emotional expression is the experience or production of art. Arts-based learning situations naturally offer a space for sensory, bodily experiences for emotional self-reflection and expression. The transformation towards empowerment if often enabled by 
connecting with challenging emotions explored through art. Listening, being present and in dialogue, emotional expression and small acts of caring are the most efficient assets of climate change education; they help combat apathy and denial.

In a broader sense, this means that rational ways of thinking need to be enriched and guided with intuitive, embodied and emotional awareness, the direct knowing of the vital conditions for human existence. Nowadays rationality is seen as instrumental and interpreted in relation to technical considerations, within a strict economic framework, related to short-term not to ultimate values' (Naess 2008, p. 88). Arne Naess (2008) suggests that the goals of rationalism should be deeply examined. Rationalism should correspond with the fundamental values and aims of our lives. Spinoza describes 'ratio' (reason) as an inner compass that points in a direction that is consistent with the active emotions and in harmony with humankind's nature or essence (Spinoza/Naess 2008, p. 86). Conscious rationalism can drive humanity towards constructive hope and sustainability in the Anthropocene.

\section{From Individualism to Creative, Collective Collaboration}

Increasing individualism is among the most significant cultural changes society has faced in the last few decades (Hofstede et al. 2010, pp. 414, 473). More individuals have attained possibilities for self-expression and choice than ever before in modern history. Increasing individualism is related to the pursuit of one's self-interest and material life goals (Kasser 2011, p. 207). It is linked to the disintegration of society and a lack of solidarity. In industrialized countries, people no longer require assistance from their community to ensure their basic needs are satisfied; independence is easier than ever.

According to some interpretations, the roots of individualism and pursuing self-interest originate as early as the Middle Ages. In the thirteenth century during the confrontation between the Christian and Islamic worlds, the elites within the church debated the nature of the soul; whether it was individual or social, possessing free will, with self-interest and ethics. Not until the eighteenth century did a deeper understanding of human subjectivity emerge, redefining the relationship between people and nature around notions of desire and self-interest (Yrjönsuuri 2013). The debates initiated in the Middle Ages are again relevant nowadays in the context of climate change. 
Capitalism necessitates and provokes competition between individuals. Our current mode of capitalism, neoliberalism, drives for maximum profit above all other considerations, which leads to ever greater individualism and competitiveness. A competitive global culture that works toward economic efficiency and productivity works against pursuit of the common good (Marglin 2008). Individuals are driven to compete for power and ownership and are expected to sell everything, even their thinking and identity. When valuing things mainly instrumentally or with money, even meaningful things such as relationships become meaningless; joy becomes diluted as nothing is sufficient.

Living communally, working for the interests of other people, giving and sharing makes people happier than receiving, sparring and living in isolation (Helliwell 2014, p. 81; Minkov 2009). Humans are on the whole social animals, and thus want to share their lives with other people. This necessitates connecting people with each other. For instance, helping other people by donating money for charity makes people more happy than using money for their own purposes (Dunn et al. 2008). Subjective happiness increases by actions for solidarity.

Climate change is a common problem that connects people locally and globally:

Who owns the solutions and knowledge needed for mitigating global warming? Encountering climate change necessitates collective thinking and collaboration. The solutions to this common global problem lie in supporting connections, not competing for benefits or controlling others. Increasing individualism has induced counter-forces to commons-thinking and open-access principles.

Individualism is often seen as problematic from the perspective of climate change. Climate change is a social problem, a problem of communities. The problem lies in the interpretation of individualism and the perception of individual benefit. Combating climate change works towards both individual and common benefit. Paradoxically, individualismpursuing individual needs and interests over the long term leads to thinking about the common good; caring for the self is necessary to be able to care for others.

Collaboration develops and broadens thinking:

Our reaction to climate change is socially constructed. Apathy is a rational and common reaction to climate change, if there is nowhere else to turn. We need real solutions and options to act. To break through the 
prevailing culture of denial of the existence, meaning or obligation of climate change, collaborative action and participatory problem-solving and learning through dialogue is needed. We need to reflect together, how we see the problem and its possible solutions. The rationale and possible answers are dependent upon collective recognition and emotional reaction (Norgaard 2011).

We need collaboration to flourish and enrich our thinking, to have more alternative visions that can be challenged from different perspectives. Sharing the experience of crisis, motivation for change, joint action towards and belief in a better future promotes hope (Ojala 2012). Real, authentic hope becomes embodied in collective action, which enables us to experience our connectedness and explore the meaning of life. Education for transformation towards sustainability should be a collective process where people working together create stories about a future with hope.

To conclude, the common good is good for individuals as well. In the Anthropocene, education must be aimed at increasing understanding of the common good and human interdependencies. Successful solutions will require discovering, respecting and responding to people's real needs (Kenrick 2009). We must cope with the illusion of autonomy, individual freedom and the psychological denial of interdependence (Weintrobe 2013 ) to encourage social learning and empower collaboration. We must transform individualism towards a focus on the common good because awareness of connections deepens and widens meaning and our perspective on life. However, individualism matters still: framed by postmaterialism, individualism may lead to personal empowerment and an increasing sense of responsibility on personal, social and societal levels.

\section{Climate Change Education in Practice}

How should we educate people for society's transformation toward sustainability? In this section, we describe the pedagogical aspects of changing in thinking and behaviour. We consider how the needed change in thinking and behavior can be supported by learning and teaching, and what kind of pedagogical solutions can be found in order to build a future that will inspire confidence and trust. We present practical solutions for climate change education starting from an eco-social approach to education, which is has been introduced as a foundational value in the new National Curriculum of Finland (2014). Then we move on 
to art-based education which we believe has great potential for climate change education as a holistic, embodied, student-centered approach which enables the integration of rational, emotional and intuitive ways of learning. In the end of this section, we explore the debate about a holistic approach to teaching and learning-phenomena-based learningwhich integrates knowledge of different school subjects together with art and science, and which necessitates collaborative learning and student ownership.

\section{The Eco-social Approach to Education}

Society cannot be constructed on short-term economic requirements. After all, a final breach of planetary boundaries means destruction of the economy. If natural resources, ecosystem services, and human beings are the only instruments for market growth, our debt to future generations will grow, and our ethics will be undermined. Thus, there is a hierarchy between ecological, social and economic elements of human well-being. It forms a science-based framework for human activity (Salonen and Konkka 2015):

1. The viability of ecosystems and the sustainable use of natural resources determine success and possibilities of society and the economy. The ecosystem possesses an absolute character-intrinsic value.

2. Implementation of human rights (justice, equality, democracy, cultural diversity) determines success of the economy. Human rights represent intrinsic value and apply under all circumstances.

3. Markets are an instrument for achieving well-being, not an end in of themselves.

The above hierarchy is the foundation of the eco-social approach to education. It does not deny the possibility of economic growth, but it determines two conditions for the growth: taking care of ecological boundaries and profound respect for human rights (Salonen 2014). Eco-social education has been introduced and implemented in the core values and overall framing of education's purpose in the new national curriculum of Finland that became law in 2016. The eco-social principles will guide the integration of instruction and the implementation of cross-curricular themes within the Finnish curriculum. According to the 
curriculum, eco-social principles should direct the development of the working and operational culture of the school. The transformation of value principles; the implementation of eco-social thinking necessitates trust, respect, and open, integrative and interactive discussion within the school communities (Finnish National board of education 2014).

Modern societies are characterized by flexible, creative, adaptable, well-informed and inventive communities, which are able to respond generously to each other (Wilkinson and Pickett 2010, p. 270). According to Abraham Maslow (1960, p. 118), the ultimate goal of human growth is fully realized humanity which highlights altruism, dedication, and the ties to other people and society. To solve the wicked problems of the Anthropocene, we need education that revolves around sensing and actualizing the good and full potential in students. Simultaneously, we will reach life satisfaction and subjective well-being because true abiding happiness cannot exist while others suffer. It comes from serving others, living in harmony with nature, and realizing our innate wisdom and the excellence of our minds. The teacher's role is to act as the conductor and orchestrator of the highest creativity and goodness found in their students. She or he aims at providing learners with the chance to achieve their highest future potential as human beings, to have access to their best sources of creativity (Scharmer and Kaufer 2013, pp. 211-212).

What we want to see is nothing less than transformative-graduates who are genuine human beings, realizing their full and true potential, caring for others-including other species-ecologically literate, contemplative as well as analytical in their understanding of the world, free of greed and without excessive desires; knowing, understanding, and appreciating completely that they are not separate from the natural world and from othersin sum manifesting their humanity fully. (Thinley 2009)

Eco-socially educated people understand that human beings are part of a fragile planetary entity. They question consumption and ownership-oriented lifestyles in the pursuit of a good life. They recognize planetary boundaries and replace material goals with immaterial elements that produce long-term satisfaction, enhance the quality of life and provide experiences of happiness. They are aware of the fact that once people have met their basic needs, their well-being is grounded in immaterial capital (Kahneman and Deaton 2010). They understand the value of cooperative relationships and generosity, 
and the fact that immaterial capital-knowledge, self-expression, freedom, affection and participation-can grow forever without any boundaries. The best experiences of life are not related to goods, but to other people. When a good life is sought by maximizing social capital, well-being is increased without negative ecological effects.

\section{Art-Based Learning}

Throughout history, art has had a strong role in societal and cultural change. Art can provoke, unveil and deconstruct cultural perceptions, hidden norms, and illustrate taboos (Löytönen and Sava 2011). For combatting climate change, there is an urgent need to unleash the artistry, creative potential and emotionally engage every human-being in visualizing and acting out a vision of sustainable well-being. Arts can transform apathy and grief into joy and empowerment and bridge the gap between theory and practice. The concepts of sustainable development or a sustainable future can be re-embedded into the world and the practice of living by art-based learning (Eernstman and Wals 2013).

Arts can offer a space and provide means for the critical issues of climate change education through emotional involvement, personal meaning making, critical thinking, active agency and creative visioning (Lehtonen 2012; 2015a, b). Arts widen the traditional ways of knowing as the rational, intuitive and embodied knowing are naturally co-operating and integrated in arts-based learning processes. Rational thinking can be enriched with imaginative, un- and preconscious material and, vice versa, scientific knowledge can serve as inspiration for artistic learning and investigative processes. Different artistic approaches and art-based methods can play an essential role in enabling education to support the cultural transformation necessary to achieve sustainability.

Contrary to objective, infallible, generalizable knowledge, art's way of knowing is subjective, embodied, emotionally loaded and engaging (Anttila 2011; Rouhiainen 2011). Appreciating one's experiences, emotional excursion and subjective processing of things is at the core of art education. Making art can have a positive impact on self-consciousness, identity construction and can strengthen empathy. Empathy and creative thinking are needed for understanding the world in its multiplicity. In the aesthetic world of art, especially in drama, participants put one's soul into other people's experiences allowing them to try out different conditions in different contexts (McNaughton 2006, 2010). 
Arts aim at widening perspectives, seeing things differently and exploring alternatives. Art's perspective to the world is dynamic. Even when watching art, not only the artist but the spectator participates actively, thereby constructing and imbuing meaning in the art. Transformations and transformative learning can take place on many levels during artistic processes. Participatory art challenges the norms of roles and identities; the idea of normality itself transforms. Individual perspectives can transform: they are enriched through dialogue and encounters with other people and their context. Evocative images and ideas are reflected in artistic action, and transformed into artistic products or performances (Lehtonen 2013). When there is an open space for expression, humour and dialogue, even social transformation can happen-resistance can be transformed into active agency (Rainio 2008; Lehtonen 2015a).

Climate change is a wicked problem that suits artistic learning:

Conflicts and tensions are optimal starting points for creativity. Emotional response can serve as inspiration for artistic expression and is involved in learning (Österlind 2012). Openness and uncertainty can be faced and managed through artistic processes. Art provides a pathway towards transformation in practice: an artist, thrown into wonder, de-familiarized and shaken up, open to the familiar becoming unfamiliar (Boeckel 2014, p. 380). Learning via the arts necessitates an ability and willingness to surrender to unanticipated possibilities, which are essential to educating for an uncertain future.

Collaborative art can address the challenging goals of climate change education through building a vital understanding of interconnectedness and the skills to cooperate, employ critical thinking and creativity. Creative collaboration can either focus on one form of art or integrate different forms of art for developing a performance, depending on the group of students or participants. Artistic process offers a space for creative inquiry of the physical and especially social reality created by different ideas, attitudes, opinions and interpretations. The critical questions of our time can be explored through creative action by making a collective piece of art, a play, a performance, dance, film, or by writing a poem or lyrics for a song, etc. A good sense of humour about tragedy can provide relief and even be empowering assets in the face of ignorance or apathy (Pihkala 2017).

Creative collaboration is a student-centered process:

Collaborative learning is student-centered by definition because student perspectives are naturally activated and participants' ideas guide the 
learning process. Creative collaboration can start from anything, but the teacher needs to set the frame for the working process. Integration of art into critical thinking and self-transformation demands concentration and applying effort to collective and individual reflection on thoughts, ideas, experiences and sensations. Furthermore, intuitive thinking can arise during the working process.

There are no right or wrong answers or mistakes. Everyone participates on their own level and relates to collaboration with their perspective and their experiences. Every idea is valuable, enriching private and collective thinking (Lehtonen 2015b). Even the phrase, "I don't have any ideas or nothing comes to my mind" is a good beginning for questioning and then embarking on artistic inquiry about prevailing attitudes. Mistakes can be used as source of inspiration as ideas are tested in practice. Learning through art happens via trial and error (Boeckel 2014, p. 365 ) because different outcomes become part of the exploration process.

To conclude, exploring and reflecting through art facilitates reflection on interconnectedness that challenges the modern dualistic understanding of the individual and society, nature and culture as segregated entities. We believe that the arts and creative collaboration have unlimited potential for climate change education.

\section{Phenomena-Based, Collaborative Learning}

In the multidimensional world of the Anthropocene, coherent approaches to learning are critical. Climate change and other wicked problems, a multidimensional world and a society in transition all challenge traditional learning methods and ideas about learning. Problembased learning that promotes systemic and holistic thinking is needed in the context of wicked problems because climate change cannot be resolved by individuals acting alone without collaboration. Collaboration is a crucial skill for education for the future and is required of both learners and teachers (Pyhältö et al. 2014).

Towards phenomena-based learning in Finland:

As a case study, we turn to the 2016 Finnish national curriculum which notably breaks from subject-based schooling. Recently, Finnish schools have been criticized for not changing as quickly as the world around them (Berner et al. 2015). The outlook of schools and classrooms might have changed but critics point to the substance and teaching and 
learning methods which have not been updated in a meaningful way. This is due in part because within the field of education there have been many '-isms' guiding new practices and reform efforts. In previous decades, constructivism and socio-constructivism have been considered the most trusted -isms generally applied to Finnish schools. Constructivist thinking skills have been one of the key explanations for Finland's good Pisa results. However, as Finland's Pisa results slide, current educational debates revolve around questions about subject knowledge and content.

Finnish schools can be described as subject oriented-structured on the basis of division between various sciences and subjects (Sahlberg 2015). Subject-orientated learning segments phenomena into different silos, concentrating learning according to internal logics, theories and observations. In the context of climate change education for instance, the concepts of atmosphere and greenhouse gases would be studied in physics and the interaction between people and the environment studied in geography and taught by experts of each field with qualified conceptual knowledge. A visual arts lesson might create environmental art work while home economics would deal with recycling materials. At best, subject-orientated climate change education gives students a multidimensional picture of a wicked global issue. But without communication between different subject-silos, the critical linkages between different domains that make climate change such a challenging problem might be missed. Fragmented or split knowledge that can result in achieving no deep understanding of climate change is a real concern and limitation when working to develop solutions (Aarnio-Linnanvuori 2013).

Recently, phenomena-based learning has been introduced as an alternative to subject-orientated learning in the new national curriculum of Finland. Although the concept of phenomena-based learning is new to the Finnish system, the ideology behind it is not. Integration of subjects has now become obligatory, but the themes and subjects involved in phenomena-based learning are chosen and planned yearly by each school. The goal is that the students build an interdisciplinary, holistic picture of selected phenomena linked to students' communities and interests. It is thus expected that studying should be both collaborative and take place in real world environments outside of schools. The learners' personal experiences, feelings and abilities to communicate together and respect each other are important enablers of phenomena-based learning (Pyhältö et al. 2014). 
Studying themes emerging from student interests:

In the Finnish phenomena-based learning process, students are encouraged and allowed to study themes of their own interest. This does not mean that students are free to do and concentrate on whatever they choose; frameworks and guidance are required for learning projects. The method of phenomena-based learning starts with a student's questions about the world around them. Several questions are likely to emerge that can then be listed in 'question cloud.' For example, questions such as: What is our future? How will we live on this planet? What kinds of innovations will we see? How will climate and vegetation change? Will there be hamburger restaurants in the future? After a collaborative reflection and analysis of the questions, the study group together with their teacher select one question to concentrate on. This study question could be related to climate change. For example, 'How will agriculture change within the next decades and what will we eat in 2030?'

After selecting the study question, students and their teacher generate ideas about how to get answers to this question and what kinds of study methods they could use in their study [AR25] process. They could for example study written texts, statistics and previous research, or they could interview farmers or make questionnaires for restaurant owners. The essential aspect of the phenomena-based learning process is that the teacher doesn't prescribe 'correct answers and methods.' Instead, the planning process (i.e., curriculum development) is collaborative. The study question can then be divided into sub-questions addressed by smaller study-groups. Each sub-group of students chooses their methods and design their own working process and schedule within the frame of the overall project schedule (Cantell 2015; Lonka and Mind the Gap Research Group 2015).

Evaluation of phenomena-based learning processes:

An important part of phenomena-based learning is the learning product. Traditionally, learning products are individually written texts and essays or group posters or other forms of presentations. For phenomena-based projects, students are free to create various kinds of presentations and products. These can be videos, art pieces, participatory theatre, portfolios, web-pages, blogs, active project days and so on (a written text can also be generated). The key idea is that new information and knowledge is not only for the sub-group itself but also for the wider public and, therefore, must be communicated. After presenting 
and publishing their work, students and their teacher together analyze the original study question and the answers they have developed through the learning process. Next they evaluate what was learned, what new knowledge was gained toward building new understanding, was some important information missing, and how did the sub-groups work (Cantell 2015).

Phenomena-based learning is deeply collaborative: it is an active learning process that develops thinking through communication and shared effort. All learners contribute their expertise, thought and experiences to a collective process resulting in an equal learning situation. Ideas are shared and developed in a relational process; every idea is as important as it enriches the collective understanding of the issue. There are no wrong questions and not just one right answer. The learning product itself is not the outcome of any individual's work, but of the group (Hakkarainen 2010). This collaborative learning model requires dialogue between students, which is often a challenge. Learners have different backgrounds, personalities, knowledge and expectations for learning processes. The key challenge in Finnish schools tends to be motivation; how to inspire students through a learning process where all can participate and feel valuable and respected (Hakkarainen 2010).

Challenges to phenomena-based learning:

There are challenges inherent in the phenomena-based approach. One is fear linked to the role and work of sub-groups of students. The teacher's role is essential as they must conduct, guide and mentor interdisciplinary (or better, transdisciplinary) work. Phenomena-based learning demands conceptual and interdisciplinary expertise or it might lead to a narrow and, therefore, limited understanding of the phenomena. For example, comprehension of the concepts of atmosphere and the impact of greenhouse gases is needed to understand climate change, how it might be managed and populations will need to adapt. Teachers incrementally changing how they teach is generally not enough. They must enable collaborative, integrated learning while building an inspiring atmosphere for learning, encouraging and supporting learners through a challenging process.

Phenomena-based learning demands collaboration between teams of experts, including teachers (Lonka and Mind the Gap Research Group 2015) because collaboration is not just about learning, it is also about teaching (Pyhältö et al. 2014). However, in Finland there is a long 
tradition of individual and autonomous teaching (one of the system's most heralded success factors). Sharing expertise and teaching practices is, therefore, unusual in Finnish schools. However, just as in the learning processes outlined above, teaching processes that are collaborative are critical as is true in many other fields. This fact will require significant changes to teacher education to fully realize the benefits of phenomena-based learning.

At best, integrative, phenomena-based and collaborative learning builds systemic understanding of the world. They offer a learner constructive pieces to build a holistic picture of the multidimensional issues facing the world and the interlinkages between them. They give a learner the elements to form her own worldview and learn about what constitutes a good life and well-being together with others. Systemic understanding requires understanding of content areas, but even more requires new learning processes; an essential tool for confronting a changing world.

\section{Pedagogical Recommendations}

The overall aim of education is to create a civilized human being who takes care of himself and his culture, the Earth and protecting possibilities for future generations (Salonen and Åhlberg 2012). In practical terms, climate change education enables students to understand the interconnectedness of planetary elements. Without a well-functioning biosphere, society cannot exist. And without society, there cannot be societal functions, including the economy. The economy is a sub-system of the larger but finite Earth system (Max-Neef 2010, pp. 203-204). This philosophical principle can be made concrete by creating good maxims such as first walk, then bike, then ride. Walking and cycling is better for health and climate. It combines egoistic and altruistic goals of life.

A main principle of climate change education is that taking care of the wellbeing of future generations does not constitute a sacrifice. This is because an individual's interests and the common good can be aligned. While it is egoistic to maximize the relevance of one's own life, it can become a civilized selfishness, because knowledge, social prosperity, arts, intellectual capital and increased humanity do not consume the planet's limited resources. Egoism and altruism do not require materiality.

Critical reflection on climate change promotes existential questions: What does it mean to be a human? What is the meaning of life? How are we related to ourselves, other people, nature, societies and the global community? The goal of climate change education is to fully realize our 
humanity - a person, who thinks critically with rich information about a wide range of global situations. The person displays an ability to imagine the predicaments of many types of people and think reflectively. Climate change education aims at critical thinking about consumerism, human identity as a consumer, and prevailing ways of pursuing happiness pushed by globalization, capitalism and advertising. Climate change education aims at increasing awareness of interconnectedness, ${ }^{3}$ post-material well-being, clarifying the goals of education and life as to meaning and purpose (Fig. 11.2).

Climate change education applies systems thinking in order to understand how the world works. According to a rational systems view, it is clear that humans are part of natural systems first, living things second, human beings third, members of society and culture fourth, and particular individuals fifth. Nature and culture should be considered as one, interrelated system. The eco-social perspective helps to understand this interconnectedness and could be applied as the basic principle for all learning and educational practices.

The understanding and response to climate change is socially constructed; each person with a unique view. In order to understand what to do about it, we need to become aware of cultural dichotomies and strive for interconnected thinking and better understanding about how we are connected to each other and nature, how we can reconnect to emotions and our bodies. Active agency can be learned only through

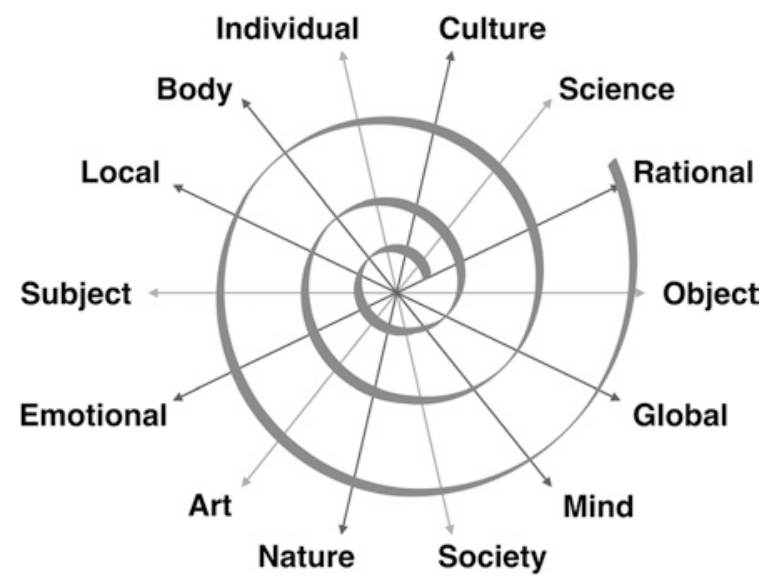

Fig. 11.2 Interconnectedness - the aim of climate change education 
practice. Embodied experiences, awareness and emotions are valuable intuitive resources for improving rational thinking, learning and knowing. Reflecting with intuition can connect us to deeper questions of human needs, desires and wishes, values and identities.

It is essential that climate education be based on a scientific understanding of socio-ecological systems and the ethical dimensions of human behaviour. Connections between local and global, between individual behaviour and communitarian practices and climate change need to be identified and illuminated through social experiences. Climate change education should be developed and enriched with contextual, subjective knowing in practice. The resulting dialogical learning situation offers open encounters where adults and young people can learn from each other and together construct pathways for a sustainable future.

Art-based learning is critical to unleash creative potential because it naturally combines different ways of knowing: pre-conscious, intuitive and rational. Arts should be used aside natural and social sciences to deepen the insight into questions traditionally approached only via scientific knowledge. Hope, courage and trust strengthen in embodied, shared experiences that explore alternative visions of a new sustainable reality where humanity is fully realized.

Hope is a pillar of the world. Great changes are possible; even wicked problems can be combatted. For instance, humans managed to stop global ozone depletion, lifespans have nearly doubled in the last century, and a universal education system as well as universal medical care have been achieved in many countries. Now there are several positive dynamics pushing towards a sustainable future such as the pursuit of meaning and purpose, stronger connection to other people and nature, the promise of security and solidarity, and the ethics of taking responsibility for others, nature and the future (Raskin et al. 2002, p. 56). Together, society is becoming stronger. As Margaret Mead once said, 'Never doubt that a small group of thoughtful, committed citizens can change the world. Indeed, it's the only thing that ever has.'

\section{Summary: Basic Elements of Climate Change Education}

- Our understanding and response to climate change is socially constructed; each person with their own perspective. 
- Nature and culture are one entity. The eco-social perspective should serve as a foundation for all learning and educative practices. Active agency can only be learned in practice.

- The global perspective: existing connections between everyday individuals and communitarian practices and climate change need to be identified and illuminated through social experiences.

- Climate change education should be developed and enriched in practice with contextual, subjective knowing.

- Reflection on embodied experiences and emotions, intuitive knowing are useful resources for rational thinking and learning. Reflecting with intuition can connect us to deeper questions of human needs, desires and wishes, values and identities.

- Art-based learning unleashes creative potential and naturally combines different ways of knowing: pre-conscious, intuitive and rational. Arts can enrich and be used aside natural and social sciences to deepen the insight of questions traditionally approached only through scientific knowledge.

- Dialogical learning situations offer open encounters where adults and young people learn from each other and together construct pathways for a sustainable future. Hope, courage and trust are strengthened through embodied, shared experiences.

\section{Notes}

1. Anthropocene is the proposed name for the epoch of human activities having significant global impact on Earth's geology and ecosystems. The term is generally used, but not officially approved by scientific community. The recognized subdivision of geological time is under debate within scientific community. Holocene is the name given to the post-glacial epoch of the past 10,000-12,000 years and Anthropocene would come after that. In this new era of anthropocene, the Age of human, nature is us and earth is in our hands as human activities impact on the environment on all scales. These impacts include the manufacturing of hazardous chemical compounds as well as significant geological forces such as land use changes, deforestation and fossil fuel burning. Humans are outcompeting natural biological, chemical and geological processes (Crutzen 2002, 2006).

2. Horst Rittel and Hans Webber (1973) launched first and defined the concept of a wicked problem with ten characteristics. Ten characteristics of the 
wicked problems are listed as follows: (1) difficulty to clearly define-every wicked problem can be considered to be a symptom of another problem; (2) definition and explanations determines the nature of the problem's solution-different stakeholders have different views of what the problem is and appropriate responses; (3) interdependencies and multi-causalitythere may be conflicting goals for those involved; (4) attempts to address wicked problems often lead to unforeseen consequences and even new wicked problems-wicked problems exist in complex systems with unpredictable, emergent behaviour; (5) unstability-understanding of the problem is constantly evolving; (6) having no clear solution, no right or wrong response, although there might be worse or better responses; (7) socially complex-it is social complexity, rather than technical complexity, that is overwhelming; (8) no clear responsibility of any one organization-these problems cross governance boundaries; (9) involve changing behaviourwith all the difficulties that poses; and (10) characterised by chronic policy failure-they have become intractable, despite numerous attempts at solutions (Rittel and Webber 1973; Australian Public service Comission 2007; Riedy 2013).

3. For historical perspectives of interconnectedness in environmental philosophy see Nash (1989).

\section{REFERENCES}

Aarnio-Linnanvuori, E. (2013). Environmental Issues in Finnish School Textbooks on Religious Education and Ethics. Nordidactica, 1, 131-157.

Allardt, E. (1976). Dimensions of Welfare in a Comparative Scandinavian Study. Sociology, 19, 227-239.

Anttila, E. (2011). Taiteen tieto ja kohtaamisen pedagogiikka. In E. Anttila (Eds.), Taiteen Jälki. Taidepedagogiikan polkuja ja risteyksiä (pp. 151-173). Helsinki: Teatterikorkeakoulu.

Australian Public Service Comission. (2007). Tackling Wicked Problems. A Public Policy Perspective. http://www.apsc.gov.au/_data/assets/pdf_file/ $0005 / 6386 /$ wickedproblems.pdf.

Bartolini, S. (2014). Buying Alone: How the Decreasing American Happiness Turned into the Current Economic Crisis. In T. Hämäläinen \& J. Michaelson (Eds.), Well-Being and Beyond-Broadening the Public and Policy Discourse (pp. 144-181). Northampton: Edward Elgar Publishing.

Berner, A.-S., Laaksolahti, H., \& Kopola, R. (Eds.). (2015). A Land of People Who Love to Learn. Helsinki: Sitra.

Boeckel, J. V. (2014). An Exploration of Practices in Arts-Based Environmental Education. Helsinki: Aalto University. 
Boyle, D., Cordon, C., \& Potts, R. (2008). Are You Happy? New Economics Past, Present and Future. London: The New Economics Foundation.

Caldeira, K., \& Davies, S. (2010). Consumption-Based Accounting of $\mathrm{CO}_{2}$ Emissions. PNAS, 107(12), 5687-5692.

Cantell, H. (2015). Näin rakennat monialaisia oppimiskokonaisuuksia. Jyväskylä: PS-kustannus.

Cook, J., Nuccitelli, D., Green, S., Richardson, M., Winkler, B., Painting, R., et al. (2013). Quantifying the Consensus on Anthropogenic Global Warming in the Scientific Literature. Environmental Research Letters, 8(2), 1-7.

Crutzen, P. (2002). Geology of Mankind: The Anthropocene. Nature, 415, 423.

Crutzen, P. (2006). The “Anthropocene". In E. Ehlers \& T. Krafft (Eds.), Earth System Science in the Anthropocene (pp. 13-18). Berlin Heidelberg: Springer.

Dewey, J. (1915). The School and Society. Chicago: University of Chicago Press.

Dittmar, H., Bond, R., Hurst, M., \& Kasser, T. (2014). The Relationship Between Materialism and Personal Well-Being: A Meta-analysis. Journal of Personality and Social Psychology, 107(5), 879.

Dunn, E., Aknin, L., \& Norton, M. (2008). Spending Money on Others Promotes Happiness. Science, 319(5870), 1687-1688.

Eernstman, N., \& Wals, A. E. J. (2013). Locative Meaning-Making: An ArtsBased Approach to Learning for Sustainable Development. Sustainability, 5, 1645-1660.

Ehrlich, P., \& Ehrlich, A. (2004). On with Nineveh: Politics, Consumption, and the Human Future. Washington, DC: Island Press.

Einstein, A. (1948). A Message to the World Congress of Intellectuals. Bulletin of the Atomic Scientists, 4(10), 295-299.

Fadel, C., Bialik, M., \& Trilling, B. (2015). Four-Dimensional Education. The Competencies Learners Need to Succeed. Boston: Center for Curriculum Redesign.

Finnish National Board of Education. (2014). Curriculum Reform 2016. http://www.oph.fi/download/174369_new_national_core_curriculum_for_ basic_education_focus_on_school_culture_and.pdf.

Goleman, D. (2006). Emotional Intelligence. New York: Bantam Books.

Gonzalez-Gaudiano, E., \& Meira-Cartea, P. (2010). Climate Change Education and Communication: A Critical Perspective on Obstacles and Resistances. In F. Kagawa \& D. Selby (Eds.), Education and Climate Change: Living and Learning in Interesting Times (pp. 13-34). London: Routledge.

Hakkarainen, K. (2010). Learning Communities in the Classroom. In K. Littleton, C. P. Wood, \& J. K. Staarman (Eds.), International Handbook of Psychology in Education (pp. 177-226). Bingley: Emerald Group Publishing.

Helliwell, J. (2014). Social Norms, Happiness, and the Environment: Closing the Circle. Sustainability: Science, Practice, \& Policy, 10(1), 78-84. 
Hirvilammi, T., \& Helne, T. (2014). Changing Paradigms: A Sketch for Sustainable Well-Being and Ecosocial Policy. Sustainability, 6(4), 2160-2175. Hofstede, G., Hofstede, G. J., \& Minkov, M. (2010). Cultures and Organizations, Software of the Mind. Intercultural Cooperation and Its Importance for Survival. London: McGraw-Hill.

Incropera, F. P. (2015). Climate Change: A Wicked Problem-Complexity and Uncertainly at the Intersection of Science, Economics, Politics and Human Behaviour. Cambridge: Cambridge University Press.

Inglehart, R. (1977). The Silent Revolution, Changing Values and Political Styles Among the Western Public. Princeton, NJ: Princeton University.

Inglehart, R. (2008). Changing Values Among Western Publics from 1970 to 2006. West European Politics, 31(1-2), 130-146.

Jackson, T. (2009). Prosperity Without Growth. Economics for a Finite Planet. London: Earthscan.

Kagawa, F., \& Selby, D. (Eds.). (2010). Education and Climate Change: Living and Learning in Interesting Times. Routledge.

Kahneman, D., \& Deaton, A. (2010). High Income Improves Evaluation of Life But not Emotional Well-Being. PNAS, 107(38), 16489-16493.

Kasser, T. (2011). Cultural Values and the Well-Being of Future Generations: A Cross-National Study. Journal of Cross-Cultural Psychology, 42(2), 206-215.

Kenrick, J. (2009). Commons Thinking. In A. Stibbe (Ed.), The Handbook of Sustainable Literacy: Skills for a Changing World (pp. 33-38). Totnes, UK: Green Books.

Lehtonen, A. E. A. (2012). Future Thinking and Learning in Improvisation and a Collaborative Devised Theatre Project Within Primary School Students. Procedia-Social and Behavioral Sciences, 45, 104-113.

Lehtonen, A. E. A. (2013). Teaching Participation and Collaboration in a Performance-Creating Project. Teoksessa. In Rannveig Björk Throrkelsdottir \& Åsa Helka Ragnarsdottir (toim.), Earth, Air, Water, Fire. Reykjavik: University of Iceland, Fliss.

Lehtonen, A. E. A. (2015a). Evaluating Students' Agency and Development of Ownership in a Collaborative Playmaking Project. The European Journal of Social and Behavioural Sciences, 14(3). http://dx.doi.org/10.15405/ejsbs.171.

Lehtonen, A. E. A. (2015b). Call for Creative Collaboration. Drama, 2015(3), 34-37.

Lehtonen, J., \& Välimäki, J. (2013). The Environmental Neurosis of Modern Man: The Illusion of Autonomy and the Real Dependence Denied. In S. Weintrobe (Ed.), Engaging with Climate Change: Psychoanalytic and Interdisciplinary Perspectives (pp. 48-51). New York: Routledge.

Lonka, K., \& Mind the Gap Research Group. (2015). Working Document I. In European Parliament (Ed.), Innovative Schools: Teaching and Learning in the Digital Era (pp. 5-46). Brussels: European Parliament. 
Löytönen, T., \& Sava, I. (2011). Taidepedagogiikka tarinoiden ja tunteiden tulkkina. In E. Anttila (Ed.), Taiteen Jälki. Taidepedagogiikan polkuja ja risteyksiä (pp. 95-121). Helsinki: Teatterikorkeakoulu.

Marglin, S. (2008). The Dismal Science. How Thinking Like an Economist Undermines Community. London: Harvard University.

Martusewicz, R. A., Edmundson, J., \& Lupinacci, J. (2014). Ecojustice Education: Toward Diverse, Democratic, and Sustainable Communities. New York: Routledge.

Maslow, A. (1954). Motivation and Personality. New York: Harper \& Brothers.

Maslow, A. (1960). Toward a Psychology of Being. Blacksburg: Wilder Publications.

Max-Neef, M. (2010). The World on a Collision Course and the Need for a New Economy. Ambio, 39(3), 200-210.

McNaughton, M. J. (2006). Learning from Participants' Responses in Educational Drama in the Teaching of Education for Sustainable Development. Research in Drama Education, 11(1), 19-41.

McNaughton, M. J. (2010). Educational Drama in Education for Sustainable Development: Ecopedagogy in Action. Pedagogy, Culture \& Society, 18(3), 289-308.

Minkov, M. (2009). Predictors of Differences in Subjective Well-Being Across 97 Nations. Cross-Cultural Research, 43(2), 152-179.

Naess, A. (2008). Life's Philosophy. Reason \& Feeling in a Deeper World. Athens, GA: The University of Georgia Press.

Nash, R. F. (1989). The Rights of Nature: A History of Environmental Ethics. Madison: University of Wisconsin Press.

Nevarez, L. (2011). Pursuing Quality of Life. From the Affluent Society to the Consumer Society. New York: Routledge.

Norgaard, K. M. (2011). Living in Denial: Climate Change, Emotions, and Everyday Life. Cambridge, MA: MIT Press.

Norton, B. (2005). Sustainability: A Philosophy of Adaptive Ecosystem Management. Chicago: University of Chicago.

Nussbaum, M. C. (2003). Upheavals of Thought: The Intelligence of Emotions. Cambridge: Cambridge University Press.

Ojala, M. (2012). Regulating Worry, Promoting Hope: How Do Children, Adolescents, and Young Adults Cope with Climate Change? International Journal of Environmental and Science Education, 7(4), 537-561.

Orr, D. W. (2009). Down to the Wire: Confronting Climate Collapse. Oxford: Oxford University Press.

Österlind, E. (2012). Emotions-Aesthetics-Education. Dilemmas Related to Students' Commitment in Education for Sustainable Development. Journal of Artistic and Creative Education, 6, 32-50. 
Pieters, R. (2013). Bidirectional Dynamics of Materialism and Loneliness: Not Just a Vicious Cycle. Journal of Consumer Research, 40, 615-631.

Pihkala, P. (2017). Environmental Education After Sustainability: Hope in the Midst of Tragedy. Draft of an article for "After Sustainability" Theme Number of Global Discourse, 7(1), 109-127.

Pyhältö, K., Pietarinen, K., \& Soini, T. (2014). Comprehensive School Teachers' Professional Agency in Large-Scale Educational Change. Journal of Educational Change, 15(3), 303-325.

Quoidbach, J., Dunn, E., Petrides, K. V., \& Mikolajczak, M. (2010). Money Giveth, Money Taketh Away: The Dual Effect of Wealth on Happiness. Psychological Science, 21(6), 759-763.

Rainio, A.-P. (2008). From Resistance to Involvement: Examining Agency and Control in a Playworld Activity. Mind, Culture, and Activity, 15(2), 115-140.

Raskin, P., Banuri, T., Gallopín, G., Gutman, P., Hammond, A., Kates, R., \& Swart, R. (2002). Great Transition. The Promise and Lure of the Times Abead. A report of the Global Scenario Group (SEI Pole Star Series Rep. No. 10).

Riedy, C. (2013). Climate Change as a Super Wicked Problem. Planetcentric. https://chrisriedy.me/2013/05/29/climate-change-is-a-super-wickedproblem/.

Rittel, H., \& Webber, H. (1973). Dilemmas in a General Theory of Planning. Policy Sciences, 4, 155-169.

Roberts, J., Tsang, J.-A., \& Manolis, C. (2015). Looking for Happiness in all the Wrong Places: The Moderating Role of Gratitude and Affect in the Materialism-Life Satisfaction Relationship. The Journal of Positive Psychology, $10(6), 489-498$.

Rouhiainen, L. (2011). Fenomenologinen näkemys oppimisesta taiteen kontekstissa. In E. Anttila (Ed.), Taiteen Jälki. Taidepedagogiikan polkuja ja risteyksiä (pp. 75-94). Helsinki: Teatterikorkeakoulu.

Sachs, J. D. (2015). The Age of Sustainable Development. New York: Columbia University Press.

Sahlberg, P. (2015). Finnish Lessons 2.0.: What Can the World Learn from Educational Change in Finland? New York: Teachers College Press.

Sale, P. (2011). Our Dying Planet. An Ecologist's View of the Crisis We Face. Berkeley and Los Angeles: University of California Press.

Salonen, A. (2014). An Ecosocial Approach in Education. In Rolf Jucker ja Reiner Mathar (toim.), Schooling for Sustainable Development: Concepts, Policies and Educational Experiences at the End of the UN Decade of Education for Sustainable Development (pp. 231-233). Berlin-Heidelberg: Springer.

Salonen, A., \& Åhlberg, M. (2012). The Path Towards Planetary Responsibility-Expanding the Domain of Human Responsibility is a Fundamental Goal for Life-Long Learning in a High-Consumption Society. Journal of Sustainable Development, 5(8), 13-26. 
Salonen, A., \& Åhlberg, M. (2013). Towards Sustainable Society—From Materialism to Post-materialism. International Journal of Sustainable Society, $5(4), 374-393$.

Salonen, A., \& Konkka, J. (2015). An Ecosocial Approach to Well-Being: A Solution to the Wicked Problems in the Era of Anthropocene. Foro de Educación, 13(19), 19-34.

Scharmer, O., \& Kaufer, K. (2013). Leading from the Emerging Future. San Fransisco: Berrett Koehler.

Schwartz, S. (1992). Universals in the Content and Structure of Values: Theoretical Advances and Empirical Tests in 20 Countries. Advances in Experimental Social Psychology, 25(1), 1-65.

Selby, D. (2010). 'Go, Go, Go, Said the Bird': Sustainability-Related Education in Interesting Times. In F. Kagawa \& D. Selby (Eds.), Education and Climate Change: Living and Learning in Interesting Times (pp. 35-54). New York: Routledge.

Snaza, N., Appelbaum, P., Bayne, S., Carlson, D., Morris, M., Rotas, N., \& Weaver, J. (2014). Toward a Posthumanist Education. JCT (Online), 30(2), 39.

Thinley, J. (2009). Presentation of Bhutan Centre for Gross National Happiness. Bhutan Centre for Gross National Happiness. www.GNHcentrebhutan.org.

Tukker, A., Huppes, G., Guinée, J., Heijungs, R., de Koning, A., Van Oers, L., et al. (2006). Environmental Impact of Products (EIPRO); Analysis of the Life Cycle Environmental Impacts Related to the Final Consumption of the EU-25. European Commission, DG JRC, Institute for Prospective Technological Studies, Technical Report EUR 22284 EN.

UN. (2013). Fertility Levels and Trends as Assessed in the 2012 Revision of World Population Prospects. New York: Department of Economic and Social Affairs, United Nation, Population Division.

Wayman, S. 2009. Futures Thinking. In A. Stibbe (Ed.), The Handbook of Sustainability Literacy. Dartington, UK: Green Books.

Weintrobe, S. (Ed.). (2013). Engaging with Climate Change: Psychoanalytic and Interdisciplinary Perspectives. New York: Routledge.

Wilkinson, R., \& Pickett, K. (2010). The Spirit Level. Why Equality Is Better for Everyone. London: Penquin.

Wolff, L.-A. (2011). Nature and Sustainability: An Educational Study with Rousseau and Foucault. Saarbrucken: Lambert Academic Publishing.

Womack, J., \& Jones, D. (2003). Lean Thinking: Banish Waste and Create Wealth in Your Corporation. New York: Free Press.

World Bank. (2012). Turn Down the Heat: Why a $4^{\circ} \mathrm{C}$ Warmer World Must Be Avoided. A Report for the World Bank by the Potsdam Institute for Climate Impact Research and Climate Analytics. Washington: World Bank.

Yrjönsuuri, M. (2013). Modernin mielen synty. In J. Hämeen-Anttila, K. Katajala, A. Sihvola, \& I. Hetemäki (Eds.), Kaikki syntyy kriisistä. Helsinki, Finland: Gaudeamus Helsinki University Press. 
Open Access This chapter is licensed under the terms of the Creative Commons Attribution 4.0 International License (http://creativecommons.org/licenses/ by $/ 4.0 /$ ), which permits use, sharing, adaptation, distribution and reproduction in any medium or format, as long as you give appropriate credit to the original author(s) and the source, provide a link to the Creative Commons license and indicate if changes were made.

The images or other third party material in this chapter are included in the chapter's Creative Commons license, unless indicated otherwise in a credit line to the material. If material is not included in the chapter's Creative Commons license and your intended use is not permitted by statutory regulation or exceeds the permitted use, you will need to obtain permission directly from the copyright holder.

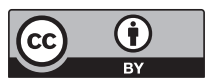

